\title{
STROKE RISK FACTORS IN PUBLIC SECTOR HOSPITALS, PESHAWAR
}

\author{
Nighat Musa1, Asghar Khan², Sher Ayub³
}

\section{ABSTRACT:}

\section{OBJECTIVES:}

To determine the incidence of risk factors regarding stroke amid diagnosed patients in public sector hospitals of Peshawar.

\section{METHODOLOGY:}

The study design was cross sectional. Duration of the study was from May till August 2018. It was conducted in two public sector hospitals of Peshawar (Khyber Teaching Hospital and Lady Reading Hospital). A total of 300 patients participated after taking informed consent. Convenient sampling technique was used. Data was entered in excel sheets and then imported for analysis in SPSS version 21.

\section{RESULTS:}

Study results showed that $62 \%$ patients were males and $38 \%$ were females. Males age distribution less than 40 years were $24 \%$ and more than 41 years were $76 \%$. Similarly, females were $21 \%$ and $79 \%$ respectively. Major medical risk factors found were hypertension, diabetes and cardiovascular diseases. The environmental risk factors were physical inactivity, smoking and obesity. The less common risk factors were alcohol and oral contraceptive use.

\section{CONCLUSION:}

The identified medical risk factors in the study can be improved and modified by regular check-ups and drug compliance. However, the environmental factors including physical inactivity, smoking and obesity can be reversed by acquiring healthy lifestyles.

KEYWORDS: Stroke, Hypertension, Obese, Diabetes, Smoking 


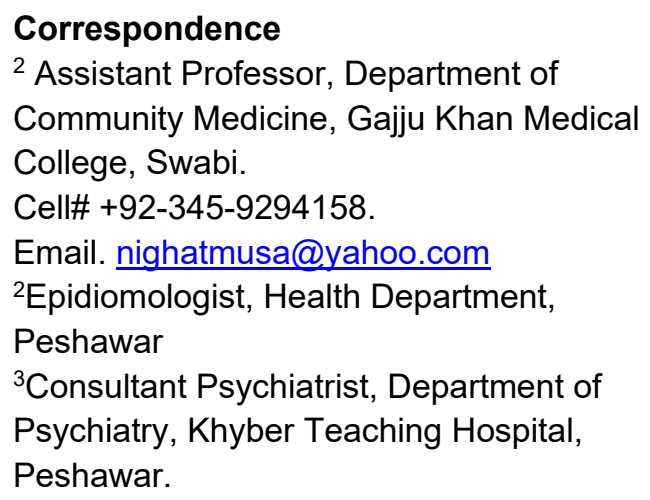

${ }^{2}$ Assistant Professor, Department of Community Medicine, Gajju Khan Medical College, Swabi.

Cell\# +92-345-9294158.

Email.nighatmusa@yahoo.com

${ }^{2}$ Epidiomologist, Health Department, Peshawar

${ }^{3}$ Consultant Psychiatrist, Department of

Psychiatry, Khyber Teaching Hospital,

Peshawar.

\section{INTRODUCTION:}

World Health Organization (WHO) defines stroke as a "clinical syndrome characterized by rapidly developing clinical symptoms and/or signs of focal and at times global applied to patients in deep coma and those with subarachnoid haemorrhage, loss of cerebral function, with symptoms lasting for more than 24 hours or leading to death, with no apparent cause other than that of vascular origin"1. It's a clinical syndrome with different causes rather than a disease. Ischemic and hemorrhagic are two main types of stroke and understanding its types aids in effective treatment and more chances of prognosis. Eighty-five percent cases of ischemic stroke occur because of obstruction of blood stream in one of the vessels supplying the brain. Rupture of an artery causes hemorrhagic stroke. Stroke is one of the leading causes of morbidity and mortality worldwide. A common cause of death in the established world after heart disease and cancer is stroke ranking third. The tests used for identifying the type of stroke are computed tomography (CT scan) and magnetic resonance imaging (MRI). The studies on epidemiology of stroke are comparatively more limited in developing than developed countries. The incidence of stroke varies in different European countries. It is estimated to be between 100 and 200 new strokes per 100,000 inhabitants per year. This imposes an enormous economic burden ${ }^{2}$. According to the American Heart Association report published in 2019 an estimated 7 million American $\geq 20$ years of age self-report having had a stroke, and the overall stroke prevalence given in the report was an estimated $2.5 \%{ }^{3}$. Its incidence in Asia, according to a rough estimate, has been increasing recently. Among Asian countries, Pakistan shares a significant burden of this devastating disease contributing towards an exponential expenditure of resources, finances, community manpower, health services and the economy as a whole $e^{4-6}$. India is the only country with population-based data. The prevalence of stroke varies in different regions of India and ranges from 40 to 270 per 100,000 rural populations and is much lower from reported prevalence of 400 to 800 per 100,000 in western countries ${ }^{6}$. Ethnic, socio-economic and dietary factors may be responsible for this variance. Retrospective analysis of patients admitted with stroke in two hospitals of the same locality some eight years ago in Karachi, Pakistan showed that out of the 12,454 cases $796 \quad(6.4 \%)$ had stroke $^{3}$. There could be many factors/causes of stroke, therefore leading to multifactorial causation. It is important to recognize and implement modifications in such factors to minimize its incidence and provide treatment. It includes medical problems like hypertension, diabetes mellitus, ischemic heart disease, infections, atrial fibrillation, and valvular heart diseases ${ }^{7-}$ 9 . The causes could be even large vessels arteritis or even undetermined in certain number of cases ${ }^{10,}{ }^{11}$. Many risk factors other than medical conditions 
contribute or increase the risk of development of stroke like hypertension, hyperlipidemias $^{12}$, smoking, physical inactivity ${ }^{13}$, alcohol consumption and various other causes ${ }^{14}$. The purpose of this study was to determine the frequency of risk factors of stroke in patients who were admitted in Peshawar hospitals.

\section{METHODOLOGY:}

It was a cross sectional study conducted on admitted patients of stroke. Two hospitals; Lady Reading and Khyber Teaching hospitals were selected for data collection. A total of 300 patients who were admitted in these hospitals with stroke were identified. Data was collected after taking informed consent from the patients. The duration of study was approximately four months. A nonprobability sampling technique was used. All the patients admitted in the hospital for treatment and who showed their willingness to participate in the study were included. Structured questionnaire was made having both open and closed ended questions. Draft questionnaire was pretested to check the feasibility and language of each question. Weight and height were also measured of every patient in order to calculate Basal Body Index. Data was collected and analysed using SPSS version 21. Results were presented in form of tables.

\section{RESULTS:}

Table 1: Gender Wise Distribution of Study Participants

\begin{tabular}{|l|c|}
\hline \multicolumn{1}{|c|}{ Gender } & N (\%) \\
\hline Male & $186(62 \%)$ \\
\hline Female & $114(38 \%)$ \\
\hline Total & 300 \\
\hline
\end{tabular}

Table 2: Age of Respondents

\begin{tabular}{|l|c|c|c|}
\hline & Male & Female & Total \\
\hline$\leq 40$ years & $45(24 \%)$ & $24(21 \%)$ & 69 \\
\hline$\geq 41$ years & $141(76 \%)$ & $90(79 \%)$ & 231 \\
\hline Total & 186 & 114 & 300 \\
\hline
\end{tabular}

Table 3: Frequency of Different Risk Factors of Stroke

\begin{tabular}{|l|c|}
\hline & Number of Cases (n=300) \\
\hline Hypertension & $63 \%$ \\
\hline Diabetes & $31 \%$ \\
\hline Cardiovascular Diseases & $17 \%$ \\
\hline Smoking & $12 \%$ \\
\hline BMl (Obese) & $09 \%$ \\
\hline Alcohol & $05 \%$ \\
\hline Oral Contraceptive Pills & $04 \%$ \\
\hline Physical Inactivity & $62 \%$ \\
\hline
\end{tabular}


Table 4: Smoking Patterns Among the Respondents

\begin{tabular}{|c|c|}
\hline & Response \\
\hline \multicolumn{2}{|l|}{ Number of Cigarettes } \\
\hline Less than 7 cigarettes & $70 \%$ \\
\hline More than 8 cigarettes & $30 \%$ \\
\hline \multicolumn{2}{|l|}{ Duration of Smoking } \\
\hline$\leq 7$ years & $26 \%$ \\
\hline $8-15$ years & $33 \%$ \\
\hline More than 16 years & $41 \%$ \\
\hline
\end{tabular}

Table 5: Physical Inactivity Among Respondents

\begin{tabular}{|l|c|}
\hline & Response \\
\hline No or negligible activity & $62 \%$ \\
\hline $\begin{array}{l}\text { Moderate activity (3/4 days } \\
\text { a week exercise) }\end{array}$ & $23 \%$ \\
\hline $\begin{array}{l}\text { Active (6 days a week } \\
\text { exercise) }\end{array}$ & $15 \%$ \\
\hline
\end{tabular}

\section{DISCUSSION:}

The main purpose of this study was to know the frequency of different risk factors contributing to expansion of stroke in Peshawar. It was understood from out of 300 cases of stroke that $62 \%$ males and $38 \%$ females reported to hospitals. Similar finding in another study showing incidence of stroke is 1.25 times higher in males as compare to females ${ }^{15}$. Increasing age is clearly the strongest determinant of the number of new cases of stroke each year. In our study more cases of stroke, admitted to hospitals were above 41 years of age. This shows that in middle age and later age groups stroke is more common as compared to younger age groups. Similar findings were shown in another study done in Texas showed that with age, chances of occurrence of stroke is more ${ }^{16}$. The medical risk factors found in our study were hypertension, diabetes and cardiovascular diseases. Hypertension is the most powerful and important modifiable risk factor causing a threefold greater risk of stroke than normotensive individuals ${ }^{1}$. Meta-analysis of different research studies done on stroke showed that hypertension or increase blood pressure could cause stroke $^{17}$. Peer review article showed that medical condition like hypertension, diabetes and cardiac diseases are risk factors of stroke ${ }^{18}$. Cardiovascular disease is common in patients with stroke. Cardiac impairment in conjunction with hypertension further increases the risk of stroke. It increases the estimated relative risk of stroke by 2 to 4 times $^{1}$. The risk of stroke in patients with diabetes mellitus is about four times that found in normal individuals ${ }^{11}$. Hypercholesterolemia and various lipoproteins fractions have been clearly associated with the severity of carotid atherosclerosis; still the serum cholesterol stroke association remains an enigma ${ }^{11}$. Regarding modifiable risk factors in our study, it was found that more common factors are physical inactivity, smoking, obesity, alcohol, and oral contraceptive pills. A study 
conducted in China showed that obesity and physical inactivity are risk factors for stroke along with medical risk factors ${ }^{19}$. Meta-analysis of over 14 studies showed strong association of smoking and stroke as compared to non-smoking and stroke ${ }^{20}, 21$. Obesity is also an established risk factor for stroke ${ }^{22}$.

\section{CONCLUSION:}

We conclude that most of the risk factors can be modified and thus the risk to stroke can be reduced. If we change our lifestyles, increase physical activity and have good planned diet we can easily control weight and increase activity makes our heart healthy. Say NO to smoking which is one of very important established risk factor and by quitting smoking we are reducing the risk of stroke among the passive smokers as well.

\section{REFERENCES:}

1. Park K. Park's Textbook of Preventive and Social Medicine. Jabalpur: M/s Banarsidas Bhanot Publishers; 2010.

2. Schellinger PD, Kaste M, Hacke W. An update on thrombolytic therapy for acute stroke. Current Opinion Neurol. 2004;17(1):69-77.

3. Benjamin EJ, Muntner $P$, Alonso $A$, Bittencourt MS, Callaway CW, Carson $A P$, et al. Heart disease and stroke statistics-2019 update: a report from the American Heart Association. Circulation. 2019;139(10): e56-528.

4. Nomani $A Z$, Nabi $S$, Badshah $M$, Ahmed S. Review of acute ischemic stroke in Pakistan: progress in management and future perspectives. Stroke Vasc Neurol. 2017;2(1):30-9.

5. Khealani BA, Hameed B, Mapari UU. Stroke in Pakistan. J Pak Med Assoc. 2008;58(7):400-3.

6. Kamal AK, Itrat A, Murtaza M, Khan M, Rasheed A, Ali A, et al. The burden of stroke and transient ischemic attack in
Pakistan: a community-based prevalence study. BMC Neurol. 2009;9(1):58.

7. Cao G, Liu W, Bi Q. Stroke in patients with infective endocarditis: a 15-year single-center cohort study. Eur Neurol. 2018;80(3-4):171-8.

8. McManus M, Liebeskind DS. Blood pressure in acute ischemic stroke. J Clin Neurol. 2016;12(2):137-46.

9. Zafar S, Bashir A, Saleem K, Arshad R, Siddique S, Rashid A. Ischemic stroke: risk factors and prediction of length of stay in hospital. Pak J Med Health Sci. 2019;13(2):327-9.

10. Li J, Yang XZ, Wang YP, Chen XL, Zhang $X$. Three-case report of embolic stroke of undetermined source. J Stroke Cerebrovasc Dis. 2017;26(7):e133-7.

11. Duarte MM, Geraldes R, Sousa R, Alarcão J, Costa J. Stroke and transient ischemic attack in Takayasu's arteritis: a systematic review and meta-analysis. $J$ Stroke Cerebrovasc Dis. 2016;25(4):781-91.

12. Boehme AK, Esenwa C, Elkind MS. Stroke risk factors, genetics, and prevention. Circ Res. 2017;120(3):47295.

13. Khan MI, Khan JI, Ahmed SI, Ali S. The epidemiology of stroke in a developing country (Pakistan). Pak J Neurol Sci. 2019;13(3):30-44.

14. Deoke A, Deoke S, Saoji A, Hajare S. Profile of modifiable and non-modifiable risk factors in stroke in a rural based tertiary care hospital-a case control study. Glob J Health Sci. 2012;4(3):15863.

15. Samai AA, Martin-Schild S. Sex differences in predictors of ischemic stroke: current perspectives. Vasc Health Risk Manag. 2015; 11:427-36.

16. Roy-O'Reilly M, McCullough LD. Age and sex are critical factors in ischemic stroke pathology. Endocrinology. 2018;159(8):3120-31.

17. Guzik A, Bushnell C. Stroke epidemiology and risk factor management. Cerebrovasc Dis. 2017;23(1):15-39. 
18. Kuklina EV, Tong X, George MG, Bansil $P$. Epidemiology and prevention of stroke: a worldwide perspective. Expert Rev Neurother. 2012;12(2):199-208.

19. Yi X, Luo H, Zhou J, Yu M, Chen X, Tan $L$, et al. Prevalence of stroke and stroke related risk factors: a population based cross sectional survey in southwestern China. BMC Neurol. 2020;20(1):1-10.

20. Pan B, Jin X, Jun L, Qiu S, Zheng Q, Pan $M$. The relationship between smoking and stroke: a metaanalysis. Medicine 2019;98(12): e14872

(Baltimore).

21. Shah RS, Cole JW. Smoking and stroke: the more you smoke the more you stroke. Expert Rev Cardiovasc Ther. 2010;8(7):917-32.

22. Haley MJ, Lawrence CB. Obesity and stroke: can we translate from rodents to patients? J Cereb Blood Flow Metab. 2016;36(12):2007-21.

\section{CONTRIBUTORS}

1. Nighat Musa - Concept \& Design; Data Acquisition; Data Analysis/Interpretation; Drafting Manuscript; Critical Revision; Supervision; Final Approval

2. Asghar Khan - Data Analysis/Interpretation; Drafting Manuscript; Supervision

3. Sher Ayub - Data Acquisition; Drafting Manuscript

LICENSE: JGMDS publishes its articles under a Creative Commons Attribution Non-Commercial Share-Alike license (CC-BY-NC-SA 4.0). COPYRIGHTS: Authors retain the rights without any restrictions to freely download, print, share and disseminate the article for any lawful purpose. It includes scholarly networks such as Research Gate, Google Scholar, LinkedIn, Academia.edu, Twitter, and other academic or professional networking sites. 